\title{
Geoethics: Master's Students Knowledge and Perception of Its Importance
}

\author{
António Almeida • Clara Vasconcelos
}

Published online: 19 December 2014

(C) Springer Science+Business Media Dordrecht 2014

\begin{abstract}
In the 1990s, the field of geoethics started its development, associated with a set of ethical principles that regulate the profession of geologists in their relationship with society and with nature. Given the importance of this field, but also its youth, 36 higher education students attending a Master's of Geology course were surveyed ( 20 were from an educational branch and 16 were from a scientific branch). The questionnaire applied to them aimed to achieve the following goals: (a) to identify the knowledge of the respondents about this new field and to verify their position about the inclusion of geoethics in the curriculum, (b) to understand how they consider the importance of geological knowledge in political decisions and (c) to investigate possible differences in the thinking of the respondents, given the specificities of their educational branches. The study concluded that the field of geoethics is unknown to the majority of the respondents. However, the recognition of its importance was also verified, after getting familiar with the definition of the concept, as well as the need for its inclusion in formal education. The respondents also considered relevant the creation of a deontological code that could provide geologists with ethical guidance. They also considered that geology should influence political decisions, but they did not consistently recognise the limits of its influence, which seems to reveal the need of a deeper understanding of the specific nature of geological knowledge when compared with other sciences. Almost all the results were similar in both groups, but the students from the educational branch offered more elaborate answers about the issues present in the questionnaire.
\end{abstract}

Keywords Geoethics · Deontological code for geologists · Geology and society · Geoethics and formal education

A. Almeida $\cdot$ C. Vasconcelos

Center of Geology of Oporto University, Oporto, Portugal

A. Almeida

e-mail: aalmeida@eselx.ipl.pt

A. Almeida

Lisbon School of Education, Lisbon, Portugal

C. Vasconcelos

Faculty of Science of Oporto University, Oporto, Portugal

C. Vasconcelos $(\square)$

Department of Geoscience, Environment and Spatial Planning, Unit of Science Teaching, Center of Geology, Faculty of Science of Oporto University, Rua do Campo Alegre, Porto, Portugal

e-mail: csvascon@fc.up.pt 


\section{Introduction}

The inanimate world has often been overlooked by conservation concerns when compared with the living world. A good example of this difference is the effort focused on biodiversity. In fact, the definition of biodiversity includes not only the species' conservation but also ecological diversity (the variety of ecosystems) and functional diversity (the environmental processes that occur in them), as defined by Miller (2012). However, the abiotic nature of these two dimensions is rarely considered in the above-mentioned efforts.

The flourishing field of environmental ethics, established since the 1960s of the twentieth century, has also devoted less attention to the value of the abiotic world. Further, the same happened to the field of bioethics, which, although proposed by Van R. Potter in 1971 with a predominantly ecological sense, related to the human impact on ecosystems, saw its most restricted meaning, proposed almost simultaneously by André Hellegers associated with the context of medical sciences while life ethics became generalised (Patrão Neves 2002).

It is true that Aldo Leopold, who many consider to be the founder of environmental ethics, proposed extending the ethical concern to the community with the inclusion of soils, water, animals and plants and considered that the land should not be regarded merely as soil but as a living system worthy of moral consideration (Leopold 1989). But, the field of environmental ethics turned out to shelter a wide range of theories in which only the ones with an ecocentric focus tend to value the non-living part of the planet. Among the authors with this approach, Rolston III (1994) clearly stands out even though he still does not break completely with the hierarchy between the biotic and the abiotic world. Although he considers life to be the best product that the Earth system produces, Rolston also believes that life is not the only value that the referred system produces. For him, inanimate beings (things) do not have an organic integrity or individuality. But, many of them have a kind of individuality that allows us to identify them from the surrounding space and have peculiarities that deserve to be highlighted like symmetry, harmony, grace, unity and spatiotemporal continuity, although they also present diffuse and discontinuous aspects. Thus, "the question now is not whether these things can suffer, nor whether they have lives they defend, nor whether they have interests or concerns" (Rolston III 1994, p. 183). Crystals, volcanoes, geysers, rivers, springs, lakes, canyons, caves, etc. are examples of creative designs of nature and should therefore be subjected to valuation, since they are products generated by the system in its formative processes, and as a consequence, they also deserve ethical consideration.

However, the hierarchy between the living and the non-living world has remained dominant in the human mind, independently of the general awareness that life only exists due to the abiotic support. Still, even acknowledging the importance of life, it is also true that the other living beings have been looked at in a merely instrumental way for centuries.

To Franklin (2008), nevertheless, we are witnessing a paradigm shift concerning the relation between humans and the living world. For Franklin, and perhaps as a result of the present environmental crisis, this new paradigm has been particularly reflected in the relationship towards animals and led to the idea that not all the needs and desires that contribute to human welfare can override, at any price, the respect that other animals deserve. Whether this paradigm shift is also being generalised to the inanimate world, it is a reflection that still needs to be made.

Traditionally, and similarly to what happened (and is still happening) to the living world, the inanimate world tends to be viewed in an instrumental way with even greater intensity. Geologists have made a significant contribution to this view because, according to Pemberton $(2001,2007)$, the majority of these professionals work in extractive industries, while, in comparison, a large number of biologists are engaged in professional activities related to biodiversity preservation. 
Even so, geology is undoubtedly a more ambiguous science than biology concerning the values it conveys. Frodeman $(2000,2003,2004)$ is one of the authors who has best been able to systematise the reasons for this ambiguity.

The destructive vision and maintenance of the idea of nature exploitation seem obvious if we look at the contribution of geology to the exploitation of resources such as water, soil, ores and other raw materials. Moreover, as stated by Frodeman (2003), by electing the hammer as a privileged instrument, the geologist emphasises the idea of mutilation of nature, which after all can be exercised by anyone, professional or apprentice.

But, Frodeman (2003) explains that this conception is only a part, maybe the dominant one, of the values that we normally associate with geology. Unlike physics and chemistry, geology is close to ecology, by choosing the field, and not the lab, as its privileged place for research. And, the field scientist work with the patterns of nature, and is dazzled with unforeseen setbacks, beauty and wisdom of the natural world, while there is an intuitive dimension that is missing in the laboratory. The simplicity of life in fieldwork is indeed fundamental to geological experience. You get a sense of reverence for the Earth, and one feels part of the system rather than disconnected from it (Turner 2000). Geology helps us to venerate processes and natural limits and, consequently, to develop a critical awareness towards technological advance. In addition, a science which is based in the field conveys an image of science epistemologically that is more realistic and socially engaged.

The notion of geologic time is also, to Williams (2000), the greatest contribution of geology to human understanding of natural history and helps us overcome the anthropocentric view of time. The same perspective is revealed by Frodeman (2004) when he states: "If the world is hundreds of millions or billions of years old, clearly we are a small part of a much greater story" (p. 162). After all, we have just arrived. And, if so, we should reflect on the legitimacy of actions that harm the planet and make us responsible for, among other things, the sixth great extinction situated between the end of the Pleistocene and the early Holocene.

Therefore, it would be unfair not to point out the growing number of geologists who have been devoting themselves to professions in the area of environmental management, particularly in the field of environmental geology and also in the field of geoconservation. Environmental geology, as stated by Almeida and Amador (2006), has sought to conciliate the instrumental view of nature exploitation with environmental concerns in studies related to natural disasters or the negative impacts of resources exploitation, such as those involving landslides, floods, soil contamination, waste disposal, pollution and rehabilitation of quarry sites.

Regarding those who work in geoconservation, the conservationist role is even clearer, although one should note the paradox arising from the fact that some of the geological sites to be protected have been discovered through human mutilating, as is the case for several places with dinosaur footprints.

To look at geodiversity, the variety within abiotic nature, in a conservationist way, is not recent. Gray (2004) points out some historical facts that are surprising for their antiquity: The serious impacts from the exploitation of stone from Salisbury Crags in Edinburgh, Scotland, motivated in 1819 a legal action to prevent further degradation; Germany established, in 1836, the first geological reserve in the world at Siebengebirge; and the USA created the Yellowstone National Park in 1872 for its scenic beauty and geological wonders. Some more specific examples could be given, but it is also Gray (2004) who considers that, in most countries, including those cited, geoconservation is poorly developed when compared to biological conservation.

Portugal is not an exception in the subalternation of the geological heritage to the biological one. However, it would be unfair not to mention the work towards the valuing of geological heritage developed by several geologists, such as Galopim de Carvalho (1994) and Brilha 
(2005). As a result of this work, in the last two decades, some geological sites received legal protection and three geoparks were created, two in Europe, Naturtejo and Arouca, and one in the Azores.

From the picture described above, and despite the positive examples set out, it is understandable that it was not untel the 1990s that the field of geoethics emerged. The term geoethics was first officially used by Václav Němec at the International Conference on Geoscience Education and Training held in Southampton, UK, in April 1993, reflecting the need for an ethical attitude towards the geosphere through the accentuation of the social responsibility of geologists. It is Němec ((n. d.)) himself who explains to us not only the context in which the term appeared, as he also mentions that in previous communications held in 1991 and 1992, he had included the reference of the need to associate ethical principles to mineral extraction. Therefore, the concept did not emerge connected to the domain of geoconservation.

However, the focus on geoethics through the issue of the exploitation of non-renewable resources turned out to be just one dimension of this new field. The concept had, in the meantime, other developments that can be identified in the definition presented by Martinez-Frías (2008):

Geoethics is a key discipline in the field of Earth and Planetary Sciences, which involves scientific, technological, methodological and social-cultural aspects (e.g. sustainability, development, museology), but also the necessity of considering appropriate protocols, scientific integrity issues and a code of good practice, regarding the study of the abiotic world. Studies on planetary geology (sensu lato) and astrobiology also require a geoethical approach (p. 1).

Within the scope of geoethics, it is relevant not only to think about how humans relate to the geosphere, but also to focus particularly on how geologists work during their academic and professional activity. Therefore, Matteucci et al. (2012) argue precisely for the need to create an ethical framework for geologists, like the ancestral code of Hippocrates applied to physicians since antiquity. As Lucchesi and Giardino (2012) also claim, geoethics gives geologists the opportunity to question themselves about the quality of their work and their contribution to the healthy progress of mankind. But, these authors advocate a more comprehensive framework and consider that "Geoethics can be also considered as part of environmental ethics, as it originates from man's inevitable question about the place he occupies in Nature, about the thoughts and motivations that animate him in his everyday life when dealing with the environment where he lives" (p. 355).

Thus, as stated in a more operational way on the website of the International Association of Promoting Geoethics (n. d.), geoethics:

- Consists of research and reflection on those values upon which to base appropriate behaviours and practices where human activities intersect the geosphere;

- Deals with the ethical, social and cultural implications of geological research and practice, providing a point of intersection for geosciences, sociology and philosophy;

- Represents an opportunity for geoscientists to become more conscious of their social role and responsibilities in conducting their activity; and

- Is a tool to influence the awareness of society regarding problems related to georesources and geoenvironment.

The new role of geologists in society is an immense challenge for all professionals engaged in the field of geosciences, because it deals with issues that are normally absent in traditional ethics, like the ownership of resources where there are multiple claims from indigenous 
groups, countries and mining companies; mining versus farming or forestry or national parks; oil and gas extraction via hydraulic fracturing and the threat to underground water supply; sustainable aquifer management; sustainable water catchment management; sustainable soil management; rehabilitation of mining sites, etc.

The introduction of an ethical dimension in science education is not exactly a new approach. For instance, in 1996, an international group produced resources for teaching scientific issues that deal with ethical implications (Fullick and Ratcliffe 1996). These issues were related to environmental problems, such as the use of pesticides, and also with genetic medicine. The conceptual basis of this work was to contribute to a better understanding of scientific concepts and of the complexity of ethical issues, and it allowed for the mobilisation of cognitive processes related with critical thought as judgment forming, supporting particular viewpoints, evaluation and analysis. However, Ratcliffe and Grace (2003) concluded that less than $40 \%$ of schools that had access to these materials would use them. Several case studies with teachers that used them also revealed mixed opinions, especially due to the time needed for these approaches.

Therefore, an ethical approach in science education can be seen as controversial. And, this can also happen with the inclusion of geoethics not only associated with geological issues that can be present in earth science disciplines, but also associated with more integrated science curricula. However, it is undeniable that democratic societies are drawn to the use of critical thinking skills, since these are essential to address the challenges associated with the exponential growth of information, different problem situations whose resolution requires decisions and the assessment of different paths and perspectives that arise about them.

\section{Methodology}

Aims and Methodological Features of the Study

Geoethics is a new field of geosciences, thus the constitution and dissemination of its knowledge are urgent among future geologists and geology teachers. This study sought to answer the following problem:

How do master's students linked to geosciences (educational and scientific branches) perceive the role of geologists in society, and simultaneously, what is their knowledge about the recent field of geoethics?

Based on this problem, we drew the following specific objectives:

1. To identify the knowledge of the respondents about this new field and analyse their position on the inclusion of geoethics in the curriculum,

2. To understand how they consider the importance of geological knowledge in political decisions, and

3. To investigate possible differences in the thinking of the respondents, given the specificities of their educational branches.

We do not intend to make any generalisation of the results but only seek to identify and understand the perceptions of students about the importance of geoethics. Thus, methodologically, the study is included in a qualitative/interpretative approach in which the researchers, working within the existing geoethics theoretical framework, tried to interpret the answers given by the respondents and sought to give them the meaning which they considered to be most correct, assuming the nature of their subjective analysis (Coutinho 2013). 


\section{Characterisation of the Sample and Its Selection Process}

It should be noted that the population with the characteristics described is not particularly large in Portugal, but we never intended to interview all the students attending master's courses such as those already referred to. But, we chose this university because it included students who would soon enter the professional world and also because, as researchers, we found ourselves linked to the training of geoscience students.

Thus, we used a convenience sample, although the choice was centred on the institutions and not entirely on the respondents. It consists of 36 students, divided into two groups, one with 20 students completing a Master's in Teaching of Biology and Geology at third cycle of basic school and secondary education (the educational branch), ${ }^{1}$ who will be referred to as EB, and another group comprised of 16 students, resulting from the sum of the students from two similar scientific master's courses (scientific branch), who will be referred to as SB.

One of the reasons for establishing the two groups was the differences in the students' educational profile, since the first group consists of individuals who will perform the function of teaching in non-higher education and the second is formed by those who will have professions related to scientific research and/or applied geology. A second reason would be the different curricula that both groups of students went through in the field of geology throughout their education. This aspect is important because it might lead to a different perception of ethical issues related with geological science.

We initially aimed to survey only students from the educational and scientific branches from one of the state science faculties in Portugal. However, due to the absence of a few students of the scientific branch on the day of the questionnaire application, we had to rethink the need to increase the size of the sample. To this end, another state science faculty in another city was contacted, and after the permission, 11 of the 12 potential respondents were surveyed. This new institution was chosen due to the proximity to the workplace of one of the researchers.

The size of the two groups is comparable, and their distribution by gender is as follows: The EB has 14 female and six male students, and the SB has nine female and seven male students. The mean age for both groups is very similar, 25.9 and 26 years old, respectively; the first group consists of students with a greater age dispersion, which varies between 20 and 47, and the second between 21 and 35. Still, most students in both groups are between 20 and 29 years old, which happens to be 16 from the EB and 13 from the SB.

\section{Design, Piloting and Questionnaire Administration}

A questionnaire was constructed to respond to the above-mentioned main objectives. It included a set of questions, some of which aimed to assess the knowledge of the respondents about geoethics and others that requested their opinion in relation to matters considered relevant and associated with this field. The questions are listed in Table 1.

The questionnaire consisted of several closed dichotomous questions (yes or no and, in the case of question 6 , the choice between two statements) but always accompanied by the request for a justification (open questions), that allowed us to better understand the thinking of the respondents. The questionnaire was divided into two parts and was administrated in a phased manner. It was found that this was the best way to allow students who knew nothing about geoethics (part I) to be able to answer the question about its importance in the curriculum (part II). With this in mind, we included in the introduction of the last question a short definition of

\footnotetext{
${ }^{1}$ Portugal has 12 years of non-superior schooling. The basic education is the first 9 years divided in three cycles, respectively, of 4, 2 and 3 years. Secondary education is the 3 years after basic education.
} 
Table 1 Questions present in the questionnaire classified according to their purpose

No. Question

Type of the question

Part I

Knowledge of the respondents about geoethics

1 Are you attending or have attended a course in geoethics? Yes or No (circle)

Closed question

2 Have you ever heard about geoethics? Yes or No (circle)

Closed question

2.1 If yes, in what context?

3 What is geoethics?

(define the concept even if in a approximate form and even if you have circled "No" in question no. 1)

4 Give two issues (examples) that are part of its domain Open question

Open question

Open question

Opinion of the respondents about issues that are relevant in geoethics

5 Do you think that geologists (scientists) should have a deontological code as it occurs in other professions? Yes or No (circle)

5.1 If yes, enumerate some principles to include in that code

Closed question

6 Which of the following statements, A or B, deserves your agreement, or at least you consider more acceptable?

Statement A - the scientific results of geologists should be the basis for specific policy options.

Statement B - the scientific results of geologists constitute a limited basis for specific policy options.

Justify your choice.

Part II

1 Geoethics is a discipline that, among others, addresses issues about scientific integrity and the need of a code of good practices in relation to the study of the abiotic world. Given this definition, do you consider that, during geology teaching in the third cycle and secondary school, subjects should integrate the field of geoethics? Yes or No (circle).

Justify your opinion.

Open question

Closed question

Open question

Closed question

Open question

geoethics, making it easier for the respondents to decide about their agreement with its introduction in the third cycle and secondary school.

A first version of the questionnaire was discussed between the members of the present research team and with another specialist in didactics of geology with regard to formulating its structure and questions. This discussion led us to design a new version which was administered to three $\mathrm{PhD}$ students in the area of science education to check the clarity of the questions included. The improvement of the questionnaire formulation was the result not only of the comments expressed by the students but also of the content of the different answers obtained and consisted of small modifications in the way that questions were formulated. The piloting process also allowed us to get an idea of the time needed to fill the questionnaire. This aspect was relevant when asking for time to be given by the curricular unit teachers for the questionnaire administration.

Its administration took place in the first state science faculty on November 26, 2012, and in the second state science faculty on January 7, 2013. This time range, a month and a half, was not considered problematic: The geographical distance between the two universities made it unlikely that there would be contact between students of both institutions, and even if this situation occurred, the collecting of the questionnaires and even its content (it was not an assessment document) made any possible contact irrelevant. 
Completing the questionnaire took about $45 \mathrm{~min}$, and it occurred during the class time of a curricular unit. The general purpose of the questionnaire was explained at the beginning of each session as well as the context in which it arose. Any concerns about questions were clarified during the completion of the questionnaire. Most students seemed to engage with the task, and some remained after the completion of the questionnaire to discuss aspects of geoethics with the researcher who was present after the task had finished.

\section{Analysis of Responses}

The open questions were subjected to content analysis, which allowed us to determine the frequency of certain topics or ideas, combining qualitative with quantitative analysis. We have applied the principles defined by Cohen et al. (2007) when identifying units of analysis. In this case, sentences revealed certain ideas which were organised in categories. The categorisation of the answers was almost always made a posteriori because they did not correspond to any known theoretical framework that allowed us to create a priori categories. However, the answers about issues that belong to the geoethics field (question 4) were categorised using the reverse process respecting the themes presented on the website of the International Association of Promoting Geoethics. The themes used were: sustainable use of georesources; correct implementation and dissemination of geological studies; disclosure and mitigation of geological risks; promotion of the social role of the geosciences and its influence in policy makers; promotion of environmentally friendly technologies; awareness of the importance of geological heritage; contribution to the scientific rigor of science museums; improvement of the relations among the scientific community, the media and the public; and application of a code of good practices associated with planetary exploration and creation of educational resources for the promotion of geoethics.

Descriptive statistics were also used to check the frequency of answers, which allowed us to compare their incidence in the two groups. Inferential statistics using the SPSS program were used to test for homogeneity between the two groups in the closed questions with the level of significance of $p \leq 0.05$. The Fisher's exact test was the appropriate test given the dimension of the sample (between 20 and 40) and also because some expected frequencies were below 5 .

Thus, we have included ideas expressed by respondents that are relevant to the purpose of the study. The recommendation of Seidman (1998) to correct some answers from a syntactic point of view was adopted, since the study did not intend to assess the linguistic performance of the respondents. Some of the mistakes made can be easily explained, since the inquiry process had a limited time, which normally prevents respondents from reviewing their own answers. As Seidman (1998) states, we considered that this was a way to value the participants written discourse and ensure their dignity throughout the process of reporting the results.

\section{Validity and Reliability}

In the process of analysing the data, different types of responses were obtained, and categorised. This was based on the grouping of similar responses, which, given the open nature of part of the questionnaire, was not always an easy task. Thus, the categorisation was first performed by each member of the research team and subsequently compared in several group sessions, and differences were discussed. The agreement was very high in almost all the answers, and in fact, the few disagreements were more related with understanding the writing than with its content. But, the major way to validate the answers of the respondents was their total or partial inclusion in 
the data analysis, as described in the previous paragraph. This inclusion allows the reader to assess the correctness of the categorisation created, leading to the judgment of the interpretation of the research team. Sometimes, the answer transcribed is the most representative one of a particular idea expressed by several respondents; quite often, we also included a few ideas that were considered relevant given their uniqueness.

The fact that it was always the same researcher administered the questionnaires in the two different contexts ensured a similar attitude preventing, for example, the provision of answer clues to the respondents.

\section{Data Analyses}

The presentation of the results followed the division of the questions according to their focus: (1) knowledge of the respondents about geoethics and (2) opinion of the respondents about issues that are relevant in geoethics.

\section{Questions About the Knowledge in Geoethics}

All the respondents answered that they had never attended a curricular unit about geoethics. In fact, it was not really a surprise because, as far as we know, there are no units offered in this field in any specific curriculum in Portugal. However, in the master's courses that the respondents were enrolled in, at least two curricular units, "Ethics and Deontology" and "Impact and Geoenvironmental Restoration", deal with ethical issues. Thus, any approach to geoethics could have been discussed, but it seems that this was not the case.

Accordingly, in the next question, which inquired whether they had ever heard of geoethics, all the respondents of SM denied this possibility. However, eight (40\%) of the respondents from the EM answered affirmatively, a difference that is statistically significant $(p=0.005)$. Of these eight, two mentioned that it was through a literature review and the media, three in the context of geoconservation, two in association with the exploitation of resources and one in the context of scientific dissemination associated with natural disasters. Nevertheless, in the concept definition, only one student from the SM said that he was not able to do that. All the others put forward a partial definition, certainly helped by the decomposition of the word geoethics: "geo" and "ethics". Table 2 presents the frequency of the different definitions given by the respondents of both groups.

Table 2 Different definitions of geoethics given by the respondents

\begin{tabular}{lll}
\hline Focus of the geoethics definition & \multicolumn{2}{c}{ Frequency } \\
\cline { 2 - 3 } & EM & SM \\
\hline Application of ethics to geology & 4 & 3 \\
$\begin{array}{l}\text { Conservation of the environment or of the geological } \\
\text { heritage }\end{array}$ & 5 & - \\
Respect for Earth (nature and earth dynamics) & 3 & 2 \\
$\begin{array}{l}\text { Deontological code of geologists } \\
\text { Careful (sustainable) exploitation of resources }\end{array}$ & 2 & 6 \\
Geologists' behaviour in the alert of populations & 2 & 4 \\
Social implications in mining & 1 & - \\
Does not know & - & 1 \\
\hline
\end{tabular}


The definitions presented contain different levels of generality. Seven of the respondents, four from the EM, immediately defined it as linked to the ethics associated with geology, a definition that corresponds to the highest level of generality. A little more focused, five respondents said that it is the respect for the Earth, represented by the respect for nature and for earth dynamics. The other respondents preferred to stress more concrete aspects, such as a deontological code for geologists, "a set of rules that must be followed in the exercise of their duties" (SM), a definition put forward by eight, six of them from the SM; the careful or sustainable exploitation of resources, "the development of rules that allow the use of geological resources" (SE), mentioned by seven respondents, four from the SE; and geoconservation, "behaviours or attitudes in order to preserve the geological environment in general" (EM), only mentioned by five respondents from the first group (EM).

However, some of the answers were less frequent but expressed ideas that we considered more curious. Two respondents from the EM said that it was the behaviour of geologists in the case of an alert to the public, which seems to be a specific case of the deontological code of geologists. As one of them clearly stated the following:

I think that Geoethics is related to ethical procedures by which geologists should govern their profession. For example, if a geologist predicts a volcanic phenomenon, he should alert the authorities to inform the population. If he didn't, he will fail on ethical grounds.

Another respondent mentioned the labour and social relations associated to resources exploitation as a subject in the field of geoethics:

I believe this is related to the extraction of certain materials (rocks), and the implications for society of who draws and who wins with that. For example, people who die and have very low salaries in coal mining comparing to the big selling profits that companies have.

With regard to the themes that the respondents considered to be part of the field of geoethics (Table 3), they were categorised using the issues previously pointed out in the analysis of response section.

It should be noted that the majority of the respondents from both groups mentioned several themes which are in fact reflected in the field of geoethics. Still, respondents from SM showed more difficulties, since five of them failed to indicate any theme. However, this difficulty, though to a smaller degree, was also observed in the respondents from the EM, as five of them were only able to mention a theme from the two that were asked.

The most common themes in both groups were related with the main categories: critical use and management of georesources (21 references, with 11 from the EM), social and environmental responsibility of geologists (15, with 11 from the EM), and the awareness of the importance of geological heritage and geodiversity (eight, with six from EM). It should be noted that all the answers that were categorised aimed to always give geologist a role in the preservation of geological heritage, in the sustainable exploitation of resources, or in the assessment of the negative impacts on individuals, society and environment. We give three examples of answers, one from each of the most frequent categories: "To respect natural resources, that means, exploring these resources moderately" (EM); "A theme is mining conditions, since miners have a shorter life expectancy" (EM); "Caring for geological sites with public relevance"(SM). 
Table 3 Themes indicated by respondents from both groups as belonging to the field of geoethics
We recall that the indication of two themes was requested

\begin{tabular}{lll}
\hline Geoethics themes & \multirow{2}{*}{ Frequency } \\
\cline { 2 - 3 } Categorisation of the answers & EM & SM \\
\hline Awareness of the importance of geological heritage & 6 & 2 \\
Geoconservation & 6 & 2 \\
Mitigation and risk management & 4 & 2 \\
Disaster prediction & 2 & 1 \\
Information to the population & 2 & 1 \\
Critical use and management of georesources & 12 & 9 \\
Exploitation of natural resources & 12 & 9 \\
Social and environmental responsibility of geologists & 11 & 4 \\
Agreement with human intervention & 1 & - \\
Changing of the geological and hydrological cycles & - & 1 \\
Territorial planning & 3 & - \\
Impact evaluation & 2 & 1 \\
Consequences for the health and the environment of & 5 & 2 \\
$\quad$ exploitation of resources and their use & & \\
Critical analysis of space exploration & 1 & - \\
Planetary exploration & 1 & - \\
Methodological rigor & 1 & 3 \\
Sample collection & & 1 \\
Lab work & & 1 \\
Data dissemination & 1 & 1 \\
Does not mention the second theme & 5 & - \\
Does not mention any theme & - & 6 \\
\hline
\end{tabular}

\section{Opinion of the Respondents About Relevant Issues in Geoethics}

The first question about issues that are relevant in geoethics inquired about the need for a deontological code for geologists. The majority of the respondents, $29(80.6 \%)$, agreed with this necessity. The highest number of opponents came from the SM group, five $(31.3 \%)$ versus two (10\%) from the EM, a difference that it is not statistically significant $(p=0.204)$. However, this difference is related with the fact that in the SM group, a higher number of respondents could not define what the field of geoethics was, also failing to mention two themes included in geoethics.

From those who agreed with the need for a deontological code, we included in Table 4 the frequency of the principles mentioned that should be part of it. As it was written by one of the respondents, "that code allows the recognition of these professionals in society and a greater professional responsibility with the demands of our society"(SM).

An analysis of the table allows us to conclude that the a higher number of respondents from the EM not only agree with the creation of a deontological code for geologists, but also offered a greater number of principles that should be part of the mentioned code. Thus, 43 principles were given by 17 respondents from this group that agree with the idea under discussion, which meant that each presented, on average, between two and three principles. In the case of the 11 respondents from the SM in a similar situation, only 17 principles were given, which meant that each one presented, on average, between one and two principles. 
Table 4 Principles that should be included in the deontological code of geologists, mentioned by the respondents from both groups

\begin{tabular}{|c|c|c|}
\hline \multirow[t]{2}{*}{ Principles associated to the deontological code of geologists } & \multicolumn{2}{|c|}{ Frequency } \\
\hline & EM & SM \\
\hline The behaviour associated with the production of knowledge and professional performance & 6 & 7 \\
\hline To discover new knowledge & 1 & - \\
\hline To reflect on the benefits and the harms of professional practice & 1 & - \\
\hline To be cautious with the means used in studies & 1 & - \\
\hline To be rigorous in their functions & & 2 \\
\hline To be discerning in sample collection & 1 & 1 \\
\hline To work in mutual aid with other scientists & 1 & - \\
\hline To respect the work of colleagues & 1 & 1 \\
\hline To provide information to peers & - & 2 \\
\hline To be objective and impartial & - & 1 \\
\hline The behaviour associated with knowledge dissemination & 8 & 2 \\
\hline To disseminate research results & 2 & 1 \\
\hline To alert the populations in case of risk & 3 & 1 \\
\hline To share results with the society and with the policy makers & 2 & - \\
\hline To encourage love for nature & 1 & - \\
\hline The behaviour associated with the exploitation of nature & 9 & 1 \\
\hline To respect natural resources and their sustainable exploitation & 8 & 1 \\
\hline To contribute to the regulation of certain practices & 1 & - \\
\hline The conduct associated with the preservation of nature & 4 & 2 \\
\hline To preserve geoenvironments and geological processes & 1 & 1 \\
\hline To preserve geological heritage & 1 & 1 \\
\hline To respect and admire nature & 2 & - \\
\hline Conduct associated with the impact of the decisions & 16 & 5 \\
\hline To take into account the social impact of the work & 6 & 1 \\
\hline To minimise environmental impacts & 8 & 1 \\
\hline To use knowledge positively & 2 & - \\
\hline To be held responsible for decisions & - & 2 \\
\hline To stay faithful to one's convictions despite political pressures & - & 1 \\
\hline Sum of principles given & 43 & 17 \\
\hline Agree with the idea but do not explain why & 1 & 1 \\
\hline Do not agree & 2 & 5 \\
\hline
\end{tabular}

The categorisation of the principles also allowed us to highlight some other differences between the two groups. The respondents from the EM showed great concern for different dimensions of the deontological code, which resulted in a wider range of ideas categorised differently. On the other hand, the respondents from the SM focused mainly on aspects related to the behaviour associated with the production of knowledge and professional performance and with the impact of their decisions on society.

With regard to the question concerning the influence of geological knowledge on policy makers, the respondents from both groups expressed themselves in favour of this influence, 
approximately, 15 (75\%) from the EM and $13(81.3 \%)$ from the SM, and the difference is not statistically significant $(p=0.709)$.

The agreement of the majority of respondents about this influence was expressed with the following ideas: "Any society depends on the geological environment and, as such, should take into account the scientific knowledge of those who study and better understand it" (EM) and "Policy options should be based on scientific results and, to this end partnerships should be established with universities" (SM). Further, this influence should apply to different fields, cited by the respondents from both groups, such as the construction of infrastructures, disaster prevention, natural resource exploitation, nature conservation or, more generally, land planning. As several respondents said: "The work of geologists allows us to determine what are the best places to build, what are the dangers associated with landslides, and what are the probabilities that natural disasters will occur" (EM); "A geologist can identify an active fault and make unfeasible the construction of a dam in a certain place or study the geotectonic characteristics of a place where a bridge or a hospital is scheduled to be built and found that it is not adequate to bear the pressures exerted by these infrastructures" (SM). With all this work, geologists are able to cause "changes in political options due to the results obtained in scientific research" (EM). The openness of politicians to such scientific knowledge would be beneficial to people, and "society will benefit from more just and sustainable options" (EM) and "this influence would have socioeconomic repercussions in a country" (SM).

However, some respondents who held this point of view also expressed their skepticism because their perception is that policy makers tend to ignore the recommendations of scientists, in general, and of geologists, in particular: "But I know that this is not what happens in politics, since there are many interests, mainly economic, involved in the positions taken by the governments" (EM); "what normally happens is that most of the time politicians ignore this knowledge and later begin to express concern for the negative consequences arising, for instance, in the case of over-exploitation of a particular ore" (SM) or, in a more contextualised way, "in Portugal, politicians frequently disregard the warnings of experts" (EM).

The eight respondents, three from the SM, who expressed disagreement with the idea, justified their position in a similar way. The essential reason is that we must take into account other dimensions, beyond the scientific one, when making political decisions. Two examples: "A geologist knows the geological reality, but does not have sufficient knowledge of the social and economic level, for example. Therefore, a policy with implications in all these dimensions cannot be based only on the opinion of a geologist" (EM); "Political choices cannot obviously be based on scientific results obtained by geologists. These results will be a basis among many others" (SM). Note that only one respondent restricted this basis to other scientific knowledge outside geology. He said: "I consider it a limited basis only because in the current context we should have a multidisciplinary consensus and take other opinions into consideration, for example, in the field of Biology" (SM).

Finally, we wanted the opinion of the respondents about the adequacy of the approach of geoethics issues in the third cycle and secondary school, where geology is part of the national curriculum. To this end, it should be noted that we presented the respondents, with a succinct definition of the concept of geoethics prior to questioning them. We felt that this definition was adequate enough for the expression of a grounded opinion even from those participants who had previously expressed a lack of knowledge about this field.

Only four respondents, three from the SM, rejected the possibility of the approach of geoethics in the mentioned cycles, a difference that was not statistically significant ( $p=$ 0.303 ). Table 5 presents the reasons given by those who agreed with the introduction of this field and reasons offered by its (few) opponents. 
Table 5 Positioning of the respondents from both groups about the introduction of geoethics in the third cycle and secondary school

\begin{tabular}{llc}
\hline The introduction of geoethics in the third cycle and secondary school & Frequency \\
\cline { 2 - 3 } & EM SM & 12 \\
\hline Yes, because... & 19 & 1 \\
It completes the approach to scientific knowledge & 1 & 3 \\
It helps the understanding between knowledge and practice & 8 & 1 \\
It helps the perception of what it is a proper respect for nature & 1 & 3 \\
It helps to understand the impact of resource consumption in the abiotic world & 7 & 4 \\
It contributes to the dimension of citizenship & 3 & - \\
It helps to develop critical thinking & - & 2 \\
Does not explain & 1 & 3 \\
No, because... & 1 & 1 \\
We should concentrate on the scientific concepts & - \\
Only in higher education & 2 \\
\hline
\end{tabular}

Two students from the EM and one from the SM gave two reasons

The idea mentioned most frequently by the respondents was associated with the necessity to explore the citizenship dimension during schooling. As two respondents said: "I think that teachers should be concerned not only with the teaching dimension but also with the education of their pupils, helping them to train the capacity to make their own choices" (EM); "Obviously, students, as citizens in an educational process, should have knowledge not strictly about scientific subjects but also about ethics" (SM).

We differentiate the response of three respondents from the EM that stressed the importance of the development of students' critical thinking. As one of them said: "Students should develop a critical view of the content that is presented to them." It seems to us that the development of this competence is certainly related to their preparation as citizens. But, because the respondents did not make this association, we chose to quantify these responses separately.

Equally frequent in both groups was the idea that geoethics helps the perception of a "proper attitude" towards nature, as expressed by eight respondents from the EM and by one from the SM. It is the idea that such an approach relates to "a code of good practice in relation to the abiotic world" (EM) or that "the students will have a new way of looking at the world around them and learn to respect it more" (EM). Four respondents, three from the EM, emphasised the idea that geoethics can help students to understand the impact of resource consumption in the geological world, an idea that seems similar to the previous one: "Students should know how to manage geological resources and be concerned with excessive consumption and its influence on the geological world" (EM), or "It is important that people realise that Earth's resources do not last forever and that we cannot dispose of them as we please" (SM). However, as these respondents referred more specifically to the issue of resources, we also decided to count these responses separately.

Another five respondents, four from the EM, stressed that the approach of the field of geoethics interconnects geological knowledge with the dimension of the impact of its application to society. We considered that the answer of the respondent from the EM exemplifies particularly well this idea: "There should be a blend of the conceptual and the procedural components of a subject. It is vitally important that after the concepts have been learned, they 
can be put into practice and with good practices!" (EM). In this type of response, the students also seem to be thinking about the sustainable use of resources. However, because this link it is not explicitly established, we decided once again to count this type of idea separately.

Finally, we considered the reasons given by those who opposed the introduction of the field of geoethics in pre-higher education, one of which was that such an approach should only be offered in higher education. As one of the respondents explained: "Only after the issues have been scientifically consolidated, should one approach the field of Geoethics" (SM).

Other respondents stated that the most important thing is to deepen scientific content: "The time that the school has to approach scientific matters is very short at the moment" (EM) or "I think that it is more important to focus the issues in a strictly scientific way" (SM).

\section{Conclusions}

After discussion of the results provided by the analysis of the responses presented in the questionnaires, we considered that it could be relevant to summarise some of the results. Later, some implications and reflections suggested by the results are discussed.

\section{Summary of the Results}

Geoethics, perhaps due to its youth as a disciplinary field, continues to be absent from the curriculum of courses attended by the respondents. Still, although many had been confronted with this concept for the first time, in particular the SM respondents, many were able to define what the field of geoethics consists of and put forward topics that are part of its domain. Our interpretation is that the respondents were certainly aided by the decomposition of the word and by using analogical thinking with the concept of bioethics, with which the students are perhaps more familiar.

The overwhelming majority of the respondents from both groups agreed with the creation of a deontological code for geologists. The respondents emphasised that the code should include principles relating to the social and environmental impact of the decisions, the conduct associated with the exploitation of nature and the dissemination of scientific knowledge in order to share it with society. However, the students from EM were more prolific in the number of principles to be included and supported the creation of this code in a higher frequency. This result is somewhat curious, given the fact that it is the respondents of the other group who will pursue a profession in the field of geology, unrelated to teaching.

Most of the respondents were of the opinion that geological knowledge should influence political power, which will be a gain for society, but revealed the suspicion that this influence does not normally not occur, because politics tends to be more influenced by economics. However, in our opinion, this influence, as it is defended by the respondents in their answers, seems to reveal a certain naive belief that there is unanimity in the scientific community about almost all subjects, some of them controversial, thus suggesting that there is only one path to follow.

The majority of the respondents from both groups expressed themselves in favour of the inclusion of geoethics in the curricula of basic and secondary education. The reasons given to support this inclusion highlight the idea that school cannot only focus on scientific content but must include other dimensions, like the ethical one, in connection with it. By so doing, school helps the development of students, focusing particularly on their education as citizens. However, the inclusion of the field of geoethics in formal education must be accompanied by a greater conceptual development, translated, for example, by a greater number of publications that address it theoretically, but also highlighting its applicability. 
It is important to be aware that this was an exploratory study with a small sample and that the results obtained are only indicators, but, even so, important for the new field of geoethics.

\section{Implications of the Study for Formal Education and Other Questions for Reflection}

Considering the conclusions mentioned above, it becomes clear that there is a need to increase the visibility of geoethics in the courses of the geology students surveyed, although it seems to us understandable that there is a lack of knowledge about this embryonic subject area.

Martínez-Frías et al. (2011) argue that since the 1970s the UNESCO, has promoted links between ethicists, scientists of Life Sciences and politicians in order to implement consistent actions on ethical issues that are associated with science and technology. Thus, similar initiatives could be developed now, mobilising geoscientists, philosophers and other science thinkers, with the purpose of contributing to the theoretical framework of this new field, which would certainly have implications in the search for a fairer path of humanity, more fraternal and sustainable, respecting the abiotic support that sustains it.

However, the inclusion of the field of geoethics in formal education must be accompanied by a greater conceptual development, translated, for example, by a greater number of publications that address it theoretically, but also highlighting its applicability. Thus, geoethics needs more contributions that lead to the strengthening of its theoretical framework, and it is with some surprise that we find that only a few authors, such as Lucchesi and Giardino (2012), have harnessed existing theories in the field of environmental ethics in order to better support their ideas, even though there are already important theories that support the value and importance of the abiotic world.

Another dimension that should follow the introduction of geoethics in the curricula is related to the role that geology can play on the above mentioned path, this is, the one that contributes to a more sustainable world. The geologist is no longer someone who appears divorced from a social, cultural and political commitment. The contour of the influence of geological knowledge on policy makers is however something controversial that has been absent from the thought of those that approach geoethics theoretically, an aspect about which the majority of respondents showed some lack of awareness.

In fact, the nature of the influence of geoethics on policy can only be assessed after an analysis of the nature of geological knowledge, since it has characteristics that are different from other sciences. First, because geology is a field science, it prevents the control of variables that is possible in lab based sciences. Secondly, the direct observation of many phenomena is often difficult, if not impossible. This stems not only from the inaccessibility of certain phenomena, like those related to the internal dynamics of the planet, but also to the historical nature of geology. Thus, "Geology often is not as precise as the more analytical side of our natures might wish it could be. In fact, Geology is inherently imprecise" (Turner 2000, p. 54). Finally, if we add the time required for many geological phenomena to occur, we have a set of characteristics that distinguish geology from other sciences, which, to Schumm (2000), results in the inability to produce quantitative laws.

Thomas (1995) stated that the greatest contribution of twentieth century science to the human intellect was the understanding of the depth and scope of the ignorance that we face. Even so, Frodeman (2010) states that scientific reasoning is often seen as a method that leads to infallible answers.

Hence, Sarewitz (2000) reminds us that "Science is sufficiently rich, diverse and balkanized to provide comfort and support for a range of subjective, political positions on complex issues such as climate change, nuclear waste, acid rain or endangered species" (p. 90). As such, science cannot be seen as an authoritative voice that can heal us of politics, but as a source of 
knowledge that can help us to understand the inevitable constraints of our knowledge and prediction (Sarewitzs 2000). Thus, defending the influence of science in political decisions will certainly outline a different approach from the ideas popularised by Francis Bacon in his work New Atlantis, published in 1627, where he suggests that not only through science will we control nature, but further, power should be given to scientists (Bacon 2007).

It seems to us that geology shows us that nature is the product of the development of many complex processes and phenomena revealed by an always difficult historical reconstruction. Therefore, this complexity offers a more modest perspective on the control of nature by emphasising the importance of context along with the limits of our future knowledge, associated with the uncertainty of geological knowledge. Following this perspective, diversity, change and uncertainty become a richness that is consistent with human nature itself, which is why geology is becoming a science that imposes limits, adding the precaution factor to our plans and ambitions. Frodeman (2003) sums this up well, stating:

In the modern era Geology was predominantly an economic discipline, supplying the raw materials needed for economic development. In the future, the central role of Earth sciences should be political, helping to define the limits that individuals and communities must live within in order to flourish (p. 117).

For this reason, Frodeman (2004) writes that geology, in the course of this century, will become a science that both says no or yes to society, imposing limits to our activities, indicating geological hazards, resource scarcity and stress of the ecosystems. Adding further support is Oelschlaeger (2000), who suggests that geology can help to overcome the dominant view that the maximisation of economic growth overrides the negative impacts on biophysical systems.

In conclusion, with this study, we hope to have contributed to a better perception of the current knowledge of geoethics in higher education and outlined some ways that can contribute to its affirmation in the near future.

\section{References}

Almeida, A., \& Amador, F. (2006). A Geologia e a Promoção de uma perspetiva Antropocêntrica da Natureza: Uma Associação Inevitável? In J. Medina, B. Aguado, J. Praia, \& L. Marques (Eds.), Simpósio Ibérico do ensino da geologia. Livro de atas (pp. 449-454). Aveiro: Universidade de Aveiro.

Bacon, F. (2007). New Atlantis. Melbourne: Book Jungle.

Brilha, J. (2005). Património geológico e geoconservação. A conservação da natureza na sua vertente geológica. Braga: Palimage Editores.

Cohen, L., Manion, L., \& Morrison, K. (2007). Research methods in education. London: Routledge.

Coutinho, C. P. (2013). Metodologia de investigação em ciências sociais e humanas. teoria e prática. Coimbra: Almedina.

Franklin, A. (2008). Animals \& modern cultures. London: Sage Publications Inc.

Frodeman, R. (2000). Preface. In R. Frodeman (Ed.), Earth matters. The earth sciences, philosophy, and claims of community (pp. vii-xiii). Upper Saddle River: Prentice Hall.

Frodeman, R. (2003). Geo-logic. Breaking ground between philosophy and the earth sciences. New York: State University of New York Press.

Frodeman, R. (2004). Philosophy in the field. In B. V. Foltz \& R. Frodeman (Eds.), Rethinking nature. essays in environmental philosophy (pp. 149-164). Bloomington: Indiana University Press.

Frodeman, R. (2010). O raciocínio geológico: a geologia como ciência interpretativa e histórica. TERRÆ DIDATICA, 6 (2), 85-99.

Fullick, L., \& Ratcliffe, M. (1996). Teaching ethical aspects of science. Totton: Bassett Press.

Galopim de Carvalho, A. M. (1994). Dinossáurios e a Batalha de Carenque. Lisboa: Editorial Notícias.

Gray, M. (2004). Geodiversity. Valuing and conserving abiotic nature. Chichester: Wiley. 
International Association of Promoting Geoethics (n. d.). http://www.iapg.geoethics.org/home/what. Accessed 5 May 2014.

Leopold, A. (1989). A Sand County Almanac. New York, Oxford: Oxford University Press.

Lucchesi, S., \& Giardino, M. (2012). The role of geoscientists in human progress. Annals of Geophysics, 55(3), 355-359.

Martinez-Frías, J. (2008). Geoethics: proposal of a geosciences-oriented formal definition and future planetary perspectives. TIERRA: Spanish Thematic Network of Earth and Planetary Sciences. http://tierra.rediris.es/ documentos/Geoethics_Tierra_Network_2008.pdf. Accessed 5 May 2014.

Martínez-Frías, J., González, J. L., \& Pérez, F. R. (2011). Geoethics and deontology: from fundamentals to applications in planetary protection. Episodes, 34(4), 257-262.

Matteucci, R., Gosso, G., Peppoloni, S., Piacente, S., \& Wasowski, J. (2012). A Hippocratic oath for geologists? Annals of Geophysics, 55(3), 365-369.

Miller, G. T. (2012). Living in the environment (17 ath ed.). Belmont: Wadsworth Publishing Company.

Oelschlaeger, M. (2000). Natural aliens reconsidered: causes, consequences, and cures. In R. Frodeman (Ed.), Earth matters. The Earth sciences, philosophy, and claims of community (pp. 107-118). Upper Saddle River: Prentice Hall.

Patrão Neves, M. (2002). A bioética e a sua exigência de fundamentação. In J. R. Silva, A. Barbosa, \& F. M. Vale (Eds.), (Coord.). Contributos para a Bioética em Portugal (pp. 137-159). Lisboa: Edições Cosmos.

Pemberton, M. (2001). Conserving geodiversity, the importance of valuing our geological heritage. Paper presented to the Geological Society of Australia National Conference, 2001.

Pemberton, M. (2007). A brief consideration of geodiversity and geoconservation. Environment, Conference Series No. 19, New Zealand Geographical Society. http://www.proceedings.com.au/quarrying2007/papers/ paper_pemberton.pdf. Accessed 5 May 2014.

Ratcliffe, M., \& Grace, M. (2003). Science education for citizenship. Teaching socio-scientific issues. Maidenhead: Open University Press.

Rolston, H., III. (1994). Conserving natural value. New York: Columbia University Press.

Seidman, I. (1998). Interviewing as Qualitative Research. A Guide for Researchers in Education and Social Sciences (2nd ed.). New York, London: Teachers College Press.

Sarewitz, D. (2000). Science and environmental policy: an excess of objectivity. In R. Frodeman (Ed.), Earth matters. The earth sciences, philosophy, and claims of community (pp. 79-98). Upper Saddle River: Prentice Hall.

Schumm, S. A. (2000). To interpret the earth. Ten ways to be wrong. Cambridge: Cambridge University Press. Thomas, L. (1995). The medusa and the snail. New York: Penguin.

Turner, C. (2000). Messages in stone: field geology in the American West. In R. Frodeman (Ed.), Earth matters. The earth sciences, philosophy, and claims of community (pp. 51-62). Upper Saddle River: Prentice Hall.

Williams, R. S. (2000). The modern earth narrative: natural and human history of the Earth. In R. Frodeman (Ed.), Earth matters. The earth sciences, philosophy, and claims of community (pp. 35-49). Upper Saddle River: Prentice Hall. 